\title{
The Cognitive Outcome in the Physical Games at the College of Students of the Basic Science in the World Islamic Sciences and Education University
}

\author{
Ibrahim A. M. Salameh ${ }^{1}$, Yaseen A. M. Al-Maharmeh ${ }^{2} \&$ Mo'een A. Oudat $^{1}$ \\ ${ }^{1}$ Faculty of Physical Education and Sport Sciences, Hashemite University, Jordan \\ ${ }^{2}$ College of Basic Sciences the World Islamic Science and Education University, Jordan \\ Correspondence: Mo'een A. Oudat, Faculty of Physical Education and Sport Sciences, Hashemite University, \\ Zarqa, Jordan. E-mail: dr.moeenodat@gmail.com
}

\author{
Received: July 25, 2013 Accepted: August 21, 2013 Online Published: September 28, 2013 \\ doi:10.5539/ies.v6n10p124 URL: http://dx.doi.org/10.5539/ies.v6n10p124
}

\begin{abstract}
The study aimed at reconnoitering the cognitive outcome in the physical games at students of the college of basic science in the World Islamic Science and Education University. The descriptive method was employed, where the sample was randomly chosen, and amounted to (16) students (males \& females) from the faculty. The sample discussed five primary dissensions: the physical, mental, emotional, and social and the educational side. The study deduced non-existence of differences with statistical indication at students of the faculty in what concerns the cognitive outcome of the physical games due to sex variable. The study results pin-pointed that the highest cognitive outcome was at the physical field following by the social field, and the lowest two fields in the cognitive outcome were on the educational field, then follows the mental field.
\end{abstract}

Keywords: cognitive outcome, physical games, education, mental, emotional, social

\section{Introduction}

The higher education sector in Jordan witnessed a great development in the number of Jordanian universities the public and private, and the number of students joining them, for associations of higher education sought to review the plans and educational programs offered by universities to their students, and the necessity of working for raising the level of cognitive outcome at students to enable the graduates deal with the requirements of the next stage and get acquainted with every new thing. And in the speech of high entrustment, the vision of his majesty King Abdullah, the second, and his wish was to arm Jordanians with skills, abilities and various experience and elevation with the cognitive level, and cultural and skillful levels through education and training. That was to graduate scientific efficiencies able to performance, development and change in the community and accompanying all challenges. But what concerns the role of the Jordanian Universities, concern increased during the last era in the physical and health education, that is through participation of university students in the various physical activities, in competitions and internal and external physical championships at the level of students in these programs, in addition to raising a theoretical subject within the education plans and electoral requirements for the bachelor stage, concerns getting students acquainted with different physical games and importance of athletics to man health.

There is a scientific renaissance witnessed at the modern communities, making large changes in most fields of contemporary life depending on every new science and cognition, to be applied and endeavored, to stir a comprehensive qualitative step to support the social and economic construction, and prepare the individual an integrated preparation at different fields of life, and occur great transformations and large changes at the fields of life (Hatamleh, 2002).

From important means in the scientific and great technological progress, witnessed at the world now, and that shared in occurring changes in individuals' life and communities, and transferring what man deduced of experience, skills and cultural and civilized values to the coming generations, where physical cognition represents one of the most important fields in the individual's life, which is considered from the cultural means, which share in the cognitive construction as a social phenomenon. (Khasawneh \& AL-zubi, 2007). 
And since large work fields at life domains and physical burdens, age requirements and technological challenges force the individual to take in cognitions, health trends and physical education in our life, and Peterson et al. (2003) assures the necessity of the following a health pattern of life, which cannot be done, except for practicing the physical activities, and health physical appropriateness, that has a direct effect on the heart health, which lead to belittling of heart disease and blood vessels. And The United States Department of Health And Human Services (USDHHS, 2012) assures that practicing physical exercises and participation in various physical games for improving the physical and health appropriateness have a great importance in individuals' health and all ages.

The public and private Jordanian universities seek to fulfill the needs and wishes of students through making the various programs available: the cultural, social, and physical programs, hoping to improve the type of graduates by the elevation of the academic level and cognition one at all life sciences. And the scientific and physical cognitive outcome is considered one of the most important elements, which share in uplifting the level of physical culture about the importance of physical and health education to uplift the level of university athletics and activities and motivate students on participating in the physical activities, prepared and offered by departments of physical activity at Jordanian Universities, and Al-Baradi'i (2004), assures on the cognitive side, which achieves integration and coordination to the individual in his different needs, and which completes the individual physiologically and psychologically, and imply the complete cognition and appropriate understanding if the skills consisting the practical activity and comprehending the values concealing behind this practice. And measuring the cognitive outcome in the various physical games of the evaluating means, in addition to the physical and skillful tests, which share in reformulating the methods and educational plans, which include the necessary cognitive sides to uplift the level of performance and participation.

The cognitive outcome is not only confined to players or athletes, but surpassed to all classes of the community at their different specializations and trends. They are in need of awareness of physical activities and employment of this cognition at the necessary way of their daily life (Hatamleh, 2002).

Preparation of students at the Jordanian universities is not only confined to the academic and cognitive preparation in a certain field of specialization, but surpassed that to assist the student to support his mental and physical abilities to improve the social relations among university students and invest leisure times, recreation and create feeling with responsibility and belongingness (Al-Maharmeh, 2009). And since "The World Islamic Science and Education University" is a newly established university. It concerned, within the last period, about preparing programs and various physical activities and introducing recently the subject of athletics and health to the university educational plans, that is to improve the quality of university life and assisting the student to improve his daily behavior, to effectively participation with the different community sectors to defend and offer cognitions in all biologic sciences.

That there is a unanimous resolution that the variant physical games share in developing human experience and uplifting its different sides and saving an atmosphere of trust, respect, reverence, justice, developing feeling of responsibility, and limiting the personal influence (Abu Areedah, 2008). And (Blair \& Church, 2004) assure that taking in with the significance of physical games and their benefits to develop atmospherically appropriateness to attain better healthy life and losing weight, especially at persons suffering from increase in weight.

And since it is a worldly trend in educating the communities with the significance of athletics for the sake of health and stabilization of social relations among students and investment of leisure times, recreation, orating feeling of responsibility and belongingness and concern about quality of life in the shadow of technology challenges that face the educational track, that is setting forth from belief that renaissance of communities and their development start from concern about the coming generations through saving and making different programs and cognitions available.

From here came the researchers concern about this study to reconnoiter the cognitive outcome of the university students for the sake of preparing an integrated developmental environment considering that activities and variant physical games support the outcome and share in cognitive and cultural elevation at all parts of life.

The cognitive outcome can be defined as:

Firstly: a group of what the individual owns from numerous cognitions acquired through academic education, or courses or experience, which appears clearly at those who own them, through the rate of cognitive outcome of a person (Gouzman \& Kozulin, 1998).

Secondly: a group of what the individual owns from numerous cognitions acquired through academic education, courses, or experience, which appears clearly at those who own them through the rate of cognitive outcome of a person, and the level of the group, which he leads as the trainer on the physical level (AL-Hawari, 2003). 
Thirdly: the group of views and ideas connected with any athletics or a game of the games including its basic skills and rules of competition that organizes and administers them, such as plans, strategies and used physical terms and symbols that communicate them, and also the common injuries at this athletics (Hatamleh, 2002).

Fourthly: it is the extent of owning by the individual from cognitions and conceptions and the values which connect with the variant physical games, practiced by him in his daily life for the sake of recreation, acquiring health and physical appropriateness.

\subsection{Research Objectives}

The study aimed at getting acquainted with the

- Cognitive outcome at students of college of basic science in the World Islamic Science and Education University, in the physical games (in the physical side, motional side, mental side, social side and the educational side).

- The variation in the cognitive outcome at students of the college of basic science in the World Islamic Science and Education University, in the physical games due to the variable of sex.

\subsection{Research Questions}

The study sought to answer the following questions:

1) What is the cognitive outcome at students of the college of basic science in the World Islamic Science and Education University, in the physical games (in the physical side, motional side, mental side, social side and the educational side)?

2) Are there differences with statistical indication at the level of indication at $(\alpha \leq 0.05)$ to the level of cognitive outcome at students of the college of basic science in the World Islamic Science and Education University ascribed to sex variable?

\subsection{Significance of Study}

Firstly: illustrating the physical cognitive outcome for students of the university, that is to uplift the physical cultural level and the significance of physical education for the sake of health.

Secondly: shedding light on points of weakness and strength in the physical programs and activities, which the university organizes, either they were at the internal or external level.

Thirdly: Raising the need of students at the university to various physical programs, lectures, and seminars to enlighten students with sciences of athletics and health.

Fourthly: the message of the university includes concern with variety of activities and elevation of the cognitive level, in addition to concern with the academic outcome.

\section{Method}

This study is considered an exploratory study. We tried to explore the reality of the cognitive outcome of sport games in the Collage of Basic Science in the World Islamic Science and Education University. The descriptive surveying method was employed, because of its appropriateness to the nature of the study. Individuals of Study consisted of students of the Collage of Basic Science in the university, registered in the subject of sports and health, whose number amounted to (160) students (males \& females). For the first semester of the academic year 2012/2013, of them (76) males and (84) females.

\subsection{Research Instruments}

A special test of the cognitive outcome was used, prepared by the researchers, where it is consisted of (25) questions, connected with numerous sides; they are (the physical Side, and the mental side, the motional side, the social side, and the educational side). The test was designed in accordance with the following steps:

- Revising the books and scientific reference related to the subject of cognitive outcome at all sport games.

- After having an outlook of researches a group of related questions was chosen, concerning the cognitive sides of university students.

The test in its final form consisted of the following:

* The physical side and consisted of (5) questions.

* The mental side and consisted of (5) questions.

* The social side and consisted of (5) questions. 
* The educational side and consisted of (5) questions.

After finishing its paragraphs, the test was shown to a group of referees with experience and specialization aiming at giving their points of view and notations about the appropriateness of questions to each side of the sides of the test.

\section{Results and Discussion}

In light of the objective of study and questioning the researchers performed the statistical processing of data which were obtained through the answers of the sample of study on the cognitive test to reconnoiter the cognitive outcome at students of the Collage of Basic Science in the World Islamic Science and Education University, which talk about the following sides: (the physical side, the mental side, the motional side, the social side, and the educational side). And in the following a show of these results in accordance with the questioning of the study in the five previous sides.

What is the cognitive outcome at students of the Collage of Basic Science in the World Islamic Science and Education University in accordance with the following sides the physical side, the mental side, the motional side, the social side, and the educational side)? To answer this question the arithmetic means and standard deviations were used for each field of the fields as a whole. The following table clears that.

Table 1. Arithmetic means and standard deviations for each field of the fields as a whole

\begin{tabular}{lllll}
\hline & The Side & Arithmetic Mean & $\begin{array}{l}\text { Standard } \\
\text { Deviation }\end{array}$ & \\
\hline 1. & The Physical & 4.25 & 0.31 & The First \\
2. & The Mental & 3.35 & 0.18 & The Fifth \\
3. & The Motional & 4.00 & 0.27 & The Third \\
4. & The Social & 4.01 & 0.19 & The Second \\
5. & The Educational & 3.55 & 0.31 & The Fourth \\
& Total & 4.01 & 0.27 & \\
\hline
\end{tabular}

It is pin-pointed from the previous table that the highest cognitive outcome at students of the Collage of Basic Science in the World Islamic Science and Education University was at the physical field where it got an arithmetic mean amounts to (4.25) and a standard deviation of (0.31). That means the cognitive outcome on this side was high, then follows the social side, which got an arithmetic mean amounting to (4.01) and a standard deviation of (0.19). That indicates the cognitive outcome was also high on this side.

This refers to that students have a knowledge of the physical abilities and have a concern with the physical side, in addition to the social side through communication with clubs and following some sport activities in different types of sport games, and also the role of media in transmission and giving this outcome, through the different sport programs.

But the lowest filed was the mental side, for it got an arithmetic mean amounting to (3.65) and a standard deviation of (0.18). That indicates that the cognitive outcome was medium on this side. Then follows the educational side, which got an arithmetic mean amounting to (3.55) and a standard deviation of (0.36). That indicates that the cognitive outcome was also medium on this side. This refers to students concern of the mental sides connected with the scientific thinking, in addition to careless about the educational sides and disconsidering them a basic objective in the different sport games. This refers to students' unawareness of the scientific domination, which needs high mental abilities. But on all fields as a whole (total) where they got an arithmetic mean amounting to (4.01) and a standard deviation of (0.27), the thing that indicates to the cognitive outcome which came high at all fields.

And may that refers to concerns of a number of students who have physical concerns, especially the males. And social concerns of the category of females. And also indicates to following of both sexes to witness competitions and different games, which decrease the mental growth, the social, the physical and the educational growth in general. 
Are there differences with statistical indication on the cognitive outcome to students of the Collage of Basic Science on all fields ascribed to the variable of sex? To answer this question the T-Test was used at each field of the fields altogether. The following table clears that.

Table 2. Arithmetic means and standard deviations and T-Test of the effect of sex in the cognitive outcome at students of the Collage of Basic Science

\begin{tabular}{lllllll}
\hline The Side & Sex & No. & $\begin{array}{l}\text { Standard } \\
\text { Deviation }\end{array}$ & $\begin{array}{l}\text { Arithmetic } \\
\text { Mean }\end{array}$ & $\begin{array}{l}\text { T. } \\
\text { value }\end{array}$ & $\begin{array}{l}\text { Statistical } \\
\text { Indication }\end{array}$ \\
\hline \multirow{2}{*}{ Physical } & Male & 76 & 0.84 & 4.51 & 0.849 & 0.403 \\
& Female & 84 & 1.16 & 4.00 & & \\
Mental & Male & 76 & 0.53 & 3.65 & 0.760 & 0.453 \\
& Female & 84 & 0.68 & 3.05 & & \\
Motional & Male & 76 & 0.97 & 4.30 & \multirow{2}{*}{1.505} & 0.144 \\
& Female & 84 & 1.26 & 3.70 & & \\
Social & Male & 76 & 0.70 & 4.00 & \multirow{2}{*}{5.54} & 0.964 \\
& Female & 84 & 0.50 & 4.01 & & \\
Educational & Male & 76 & 0.62 & 3.45 & \multirow{2}{*}{5.888} & 0.788 \\
& Female & 84 & 0.58 & 3.65 & & \\
Whole Total & Male & 76 & 0.79 & 4.02 & \multirow{2}{*}{0.891} & 0.381 \\
& Female & 84 & 0.67 & 4.00 & & \\
\hline
\end{tabular}

It is clear from table 2 that there are no differences with statistical indication at $(\alpha=0.05)$ ascribed to the variable of sex at all sides and the instrument as a whole. For the value of (T) for the whole degree of sex effect $(0.891)$ and with statistical and indication amounted to (0.381), and it is statistically indicative at the level of indication $(\alpha=0.05)$.

And that may refer to social concerns at females more than at males; meanwhile the physical concerns at the males are higher than at females, in addition to the mental, educational and motional sides of both sexes through following some different sport games.

\subsection{Conclusions}

There are no differences with statistical indication at students of the Collage of Basic Science in the World Islamic Science and Education University, in what concerns the cognitive outcome in small games between males and females.

\subsection{Recommendations}

- Concentration on cognitive side concerned with sports games by instructors of practical subjects, to be introduced to the student in a deeper and larger form, because of what these sides have of importance in bringing up a generation able to confront requirements of life.

- Implementing these sides related to sport games practically applying to stabilize them at university students, who in turn implement them on students at schools.

- Preparing celebrations and activities concerning the small games in what achieves benefits for the individual and the community.

- Making more studies, scientific studies in the field of cognitive outcome to reconnoiter the significance of the correct test of the instructor of physical education.

\section{References}

Abu Aa'reedah, A. (2008). The cognitive outcome at players of the first degree clubs in swimming and the basketball in human rights. Unpublished Master thesis, University of Jordan. 
Al-Baradi'i, R. M. (2004). Building a test to measure the cognitive outcome at taekwondo trainers in Jordan. Unpublished Master thesis, University of Jordan.

Al-Hawari, M. M. (2003). The scientific cognitive outcome at karate trainers in Jordan. Unpublished Master thesis, Yarmouk University, Jordan.

Al-Maharmeh, Y. (2009). Evaluation of programming and physical activities at department of physical activity at the Jordanian universities in light of the comprehensive quality requirements. Unpublished Doctoral dissertation, University of Jordan.

Gouzman. R., \& Kozulin. A. (1998). Enhancing cognitive skills in blind learners. Paper presented at the annual conference of the British psychological association education section. Exeter, UK- September, 1998.

Hatamleh, M. (2002). The cognitive outcome for trainers and players of the volleyball in Jordan. Unpublished Master thesis, University of Jordan.

Khasawneh, A., \& AL-ZUBI, Z. (2007). The scientific cognitive outcome at players and trainers of 'track and field' games in Jordan. Al-Najah Journal for Research: Human Sciences, 21(3), 619-656.

Laurie, L. H. (1995). Knowledge of physical education and voluntary coaches in Hong Kong secondary schools in Lipinski, Souiski, Hong Kong.

Petrson. D. F., Degenhardt. B. F., \& Smith C. M. (2003). Correlation between prior exercise and present health and fitness status of entering medical students, original contribution. The Journal of the American Osteopathic Association, 103(8), 361-366.

U.S. Department of Health and Human Services. (2002). Physical activity fundamental to preventing disease. Retrieved from April 15, 2013, from http://www. hhs.gov

\section{Copyrights}

Copyright for this article is retained by the author(s), with first publication rights granted to the journal.

This is an open-access article distributed under the terms and conditions of the Creative Commons Attribution license (http://creativecommons.org/licenses/by/3.0/). 